\title{
General prevention, PPPM concepts in traditional medicine, individualised exercise training
}

\author{
ON THE EMERGING ROLE OF NEUROIMAGING IN \\ DETERMINING FUNCTIONAL AND STRUCTURAL \\ BRAIN INTEGRITY INDUCED BY PHYSICAL \\ EXERCISE: IMPACT FOR PREDICTIVE, PREVEN- \\ TIVE AND PERSONALIZED MEDICINE \\ Boecker $H$ \\ Radiologische Universitätsklinik, FE Klinische Funktionelle \\ Neurobildgebung, Rheinische Friedrich-Wilhelms-Universität \\ Bonn, Sigmund-Freud-Str. 25, 53127 Bonn, Germany
}

Regular physical exercise promotes fitness and reduces cardiovascular risk factors, thereby contributing to maintenance of physical health, reduction of cardiovascular mortality, and improved life expectancy. There is a growing body of evidence, both from animal work and from human epidemiological and longitudinal intervention studies, that regular physical exercise also impacts directly on the central nervous system, mediating structural brain integrity and improving cognitive functioning. Modern neuroimaging approaches, in particular magnetic resonance imaging (MRI) based techniques, provide a powerful means to non-invasively study the effects of physical exercise on human brain structure and function in vivo. Positron emission tomography (PET) is another interesting technique, as it allows for quantification of neuroreceptor binding status of dedicated ligands in athletes, thereby, unravelling the central neurochemistry of exercise. Employing these techniques in exercise sciences will allow for determining central mechanisms of body-brain interactions, both, in health and disease states. It is expected that this may propagate individualized exercise training regimens for disease prevention and, ultimately, adapted applications for prevention and slowing down disease progression in neurodegenerative conditions. At current, however, these imaging techniques are largely based on inter-subject averaging and their impact for personalized medicine with the goal of promoting preventative and personalized healthcare remains to be determined.

\author{
SHIFT WORK AND BREAST CANCER \\ Richter $K$ \\ Clinic for Psychiatry and Psychotherapy, Clinic Nuernberg \\ \& Faculty for social work, GSO University Nuernberg, \\ Germany
}

Shift work increases the risk for breast cancer. The International Agency for Research on Cancer (IARC) has classified shift work as probably carcinogenic to humans (Group II A Carcinoma). This classification as probably carcinogenic is based on the fact that there is only limited evidence in humans but sufficient evidence from studies with laboratory animals. IARC is an institution of WHO. Shift work is included in the risk classification that categorises it as being at the same level as harming affects by UV radiation and acrylamides (ERREN).

Poor light exposure during the night, disruptions of the sleep-wake-rhythm and the concomitant interruption of melatonin production are altogether likely to contribute to the development of breast cancer. Fluctuating melatonin levels modulate sex hormones synthesis and their consequent levels in the blood. This in turn increases the risk of hormone-induced diseases including breast carcinoma. Several international studies demonstrate an increased presence of breast cancer in nurses working predominantly in the night. Therefore, it is recommended to offer them the opportunity for regular preventive medical check-ups, since they belong to a risk group predisposed to breast cancer. Chronotype (early versus late sleepers) is the most important protector for adapting to shift work. After working in the morning shift, early sleepers sleep better and longer. In contrast, late sleepers better and longer after working in the night shift. This fact should be taken into consideration by employers when scheduling the employees either for morning or night shift according to individual chronotypes. This is a secure way how to prevent the employees against several pathologies. 
Further studies to investigate, whether shift work promotes the occurrence of breast cancer in women with a positive family history are essential to be carried out. Should shift work turn out to represent a risk for breast cancer particularly increased in women with a positive family history, this will have a direct influence on the career choice of this patient cohort. Consequently, these individuals should be counselled in a way to persuade them to choose a career not related to shift work. In this process, the counselling activity could be triggered by health insurances.

\section{AYURVEDA, THE PARADIGM FOR PERSONALIZED MEDICINE}

Morandi $A^{1,2}$, Tosto $C^{l}$, Dalla Libera $D^{1,2,3}$

${ }^{1}$ Ayurvedic Point, C.so Sempione 63, 20149 Milan, Italy

${ }^{2}$ SSIMA, Italian Scientific Society for Ayurvedic Medicine, C.so Sempione 63, 20149 Milan, Italy

${ }^{3}$ IRCCS San Raffaele, DIMER, Dept of Neurology, Via Olgettina 48, 20132 Milan, Italy

There is growing evidence that our next-future medical approach will consists of personalized medicine -based on pharmacogenomics, proteomics, metabolomics, physiomics. This approach developed out of the realization that patients diagnosed with the same disease often respond differently to drugs. Furthermore, proper "clever" individualized treatment is particularly difficult to find in disease early phases where the presence of biomarkers is still poor. Innovative tools are necessary to assist practitioners in making adequate therapeutic choices according to each patient in order to optimize the benefit-to-risk ratio of drugs. Recently, the treatment tailoring upon individual genetic profile has been proposed. However, nature is more complex and we now know that we have to focus on genes functions and interactions and gene products rather than on genes themselves. Even so the interplay between genes and environmental influences remains elusive. In addition, system biology is still at its infancy, being extremely expensive and not affordable everywhere.

We propose an integrated approach based on a traditional medicine view to transform our understanding of complex diseases and best prevent them.

Ayurveda-India's traditional system of medicine-emphasize the importance of preventing before treating illness through body-mind awareness and lifestyle. It looks beyond the purely structural view by considering life as a complex interrelationship of several forces. It has a time-honored philosophical and experiential basis, being founded on Apta or knowledge from previous experience, Pratyaksha or data derived from observation, Anumana or inference due to evidence of constant association, Upamana or evidence by variables analogy and Yukti or experimental data.

According to Ayurveda each individual has a unique constitution (prakrti) with different physical, physiological, metabolic and mental facets. The 3-fold-classification (tridosha theory) identifies principles of motion (Vata), transformation (Pitta) and cohesion (Kapha) as discrete phenotypic groupings,as it is also verifiable through genetics [1-3]. The basis of dosha are the five elements called Akasa (ether), Vayu (air), Tejas (fire), Jala (water) and Prithvi (earth), representing different stages on matter density expressing several qualities (mahabhuta theory). Prakrti is characterized by peculiar combinations of Dosha. A harmonious state of the three doshas means health while an imbalance, possibly an excess (vriddhi) or deficiency (kshaya) may lead to disease $[4,5]$. Correction of dosha to their original state is required to restore health. This may be obtained through lifestyle interventions [6].

Prakrti determines disease predispositions and may predict individual's drugs sensitivity and response [7]. In fact, differences are evident for biochemical, hematological and gene-expression parameters between Prakriti types [8]. For instance, Aggarwal et al. showed that a peculiar genotype determining higher expression of EGLN1 was more frequently found in people with Kapha prakrti and associated with high-altitude pulmonary edema [9]. Variability in heart rate and arterial blood pressure was also demonstrated in patients with different prakrti, evaluated through a self-assessment questionnaire [10]. Ayurveda consider also patient's unique disease stage due to organism's response to disease and environmental conditions.

Definition of research protocols according to Ayurvedic Logic is desirable in order to enforce a personalizedmedicine approach. Ayurveda and Western Medicine can be tunefully integrated with reciprocal benefits [11].

\section{References}

1. Patwardhan B, Bodeker G. Ayurvedic genomics: establishing a genetic basis for mind-body typologies. J Altern Complement Med. 2008;14(5):571-6.

2. Hankey A. The scientific value of Ayurveda. J Altern Complement Med. 2005;11(2):221-5.

3. Hankey A. A test of the systems analysis underlying the scientific theory of Ayurveda's Tridosha. J Altern Complement Med. 2005;11(3):385-90.

4. Bhushan P, Kalpana J, Arvind C. Classification of human population based on HLA gene polymorphism and the concept of Prakriti in Ayurveda. J Altern Complement Med. 2005;11(2):349-53.

5. Chopra A, Doiphode VV. Ayurvedic medicine. Core concept, therapeutic principles, and current relevance. Med Clin North Am. 2002;86(1):75-89.

6. Sharma S, Puri S, Agarwal T, Sharma V. Diets based on Ayurvedic constitution - potential for weight management. Altern Ther Health Med. 2009;15(1):44-7. 
7. Ghodke Y, Joshi K, Patwardhan B. Traditional Medicine to Modern Pharmacogenomics: Ayurveda Prakriti Type and CYP2C19 Gene Polymorphism Associated with the Metabolic Variability. Evid Based Complement Alternat Med. 2011; doi:10.1039/ecam/nep206.

8. Prasher B, Negi S, Aggarwal S, Mandal AK, Sethi TP, Deshmukh $\mathrm{SR}$, et al. Whole genome expression and biochemical correlates of extreme constitutional types defined in Ayurveda. J Transl Med. $2008 ; 6: 48$.

9. Aggarwal S, Negi S, Jha P, Singh PK, Stobdan T, Pasha MA, et al. EGLN1 involvement in high-altitude adaptation revealed through genetic analysis of extreme constitution types defined in Ayurveda. Proc Natl Acad Sci U S A 2010;107(44):18961-6.

10. Tripathi PK, Patwardhan K, Singh G. The basic cardiovascular responses to postural changes, exercise, and cold pressor test: do they vary in accordance with the dual constitutional types of ayurveda? Evid Based Complement Alternat Med. 2011; doi:10.1155.2011/251850.

11. Narahari SR, Ryan TJ, Bose KS, Prasanna KS, Aggithaya GM. Integrating modern dermatology and Ayurveda in the treatment of vitiligo and lymphedema in India. Int J Dermatol. 2011;50(3):310-34.

\section{INNOVATIVE PSYCHOSOMATIC MARKERS FOR PREDICTION, PREVENTION AND PERSONALISED TREATMENT OF NON-COMMUNICABLE DISEASE \\ De Meester F, Wilczyńska A \\ DMF-PL, Gliwice, Poland (www.dmfrontiers.pl)}

Vascular rhythms (secondary risk factors) and blood fatty acids (primary risk factor) are two so far undetected critical factors that heavily impact on health.

VVDs: vascular variability disorders; $\Omega 6 \mathrm{~S}$ : omega-6 status;

NCDs: non-communicable diseases.

Abnormalities in the variability of blood pressure and heart rate - commonly referred to as vascular variability disorders or VVDs - are impossible to detect in a conventional office visit, yet can raise the relative cardiovascular disease risk (gauged by the occurrence of a morbid event over the next 6 years) from $9 \%$ to $100 \%$. These risks, silent to the subject involved and the conventional care-provider, notably the risk of circadian hyper-amplitude tension or CHAT can usually be reduced if not reversed by chronobiological self-help, with or without pharmacological approaches [1]. The proportion of omega- 6 in tissue highly unsaturated fatty acids or HUFA is a surrogate endpoint in successful primary

\begin{tabular}{lcccc}
\hline Innovative & $\begin{array}{c}\text { Psycho } \\
\text { VVDs }\end{array}$ & $\begin{array}{c}\text { Somatic } \\
\Omega 6 \mathrm{~S}\end{array}$ & $\begin{array}{c}\text { Markers } \\
\rightarrow\end{array}$ & NCDs \\
\hline Predictive & + & + & & \\
Personalized & + & + & & \\
Preventive & + & + & \\
Non Invasive & + & + & \\
Non Obtrusive & + & + & \\
\hline
\end{tabular}

prevention of coronary heart disease or CHD. The $\%$ omega -6 HUFA helps predicting the likely risk of a fatal event. This surrogate endpoint gives each individual a clear indication of personal risk and also an indication of success in personal compliance with well-focused nutritional advice. People with more than half of their HUFA as omega- $6(\Omega 6 \mathrm{~S})$ are at a greater risk of death from CHD than those with less than half [2].

The two factors are at the basis of a current tentative mindbody approach to preventive personalized medicine that aims at (1) targeting variability, (2) enhancing performance, and (3) detecting pre-metabolic syndrome (pMS).

\section{References}

1. Halberg F, Cornélissen G, Otsuka K, Siegelova J, Fišer B, Dušek J, et al. Extended Consensus on Need and Means to Detect Vascular Variability Disorders (VVDs) and Vascular Variability Syndromes (VVSs). Int J Geronto-Geriatrics. 2008;11:119-46.

2. Lands B. A critique of paradoxes in current advice on dietary lipids. Prog Lip Res. 2008;47:77-106.

\section{THE EFFECT OF THE SUPPLEMENTATION OMEGA 3 FATTY ACIDS TO LIPIDS AND ANTHROPO- METRIC PARAMETERS IN THE OBESE YOUNG VOLUNTEERS}

Suchanek $P^{1,2}$, Hubacek $J A^{1,2,3}$, Kralova Lesna $I^{1,2}$, Pinekerova $V^{l}$, Stupalova $R^{l}$, Stankova $N^{l}$

${ }^{1}$ Institute for Clinical and Experimental Medicine, Prague, Czech Republic

${ }^{2}$ Centre for Cardiovascular Research, Prague, Czech Republic

${ }^{3}$ South Bohemia University, Faculty of Public Health and Social Studies, Ceske Budejovice, Czech Republic

Aim: To ascertaine the effect of the supplementation of the polyunsaturated fatty acids to the lipids and anthropometric parameters in the obese healthy probands, during 6 weeks of treatment.

The Group and Method: 95 healthy probands, aged 1218 years, body mass index $>27 \mathrm{~kg} / \mathrm{m}^{2}$ were included. The group was divided into 2 arms. Arm A (30 probands) - the omega 3 fatty acids $360 \mathrm{mg} /$ day was added (300 mg DHA, $42 \mathrm{mg}$ EPA-Haliborange $\left.{ }^{\circledR}\right)$. Arm B (65 persons) normal reduction diet, without the supplementation of the fatty acids. All parameters examinated (total cholesterol, triglycerides, HDL, LDL cholesterol, blood pressure, apolipoprotein $\mathrm{B}$, body mass index, circumference of the waist, $\mathrm{C}$ reactive protein) were analyzed at the start-point of the study and after 6 weeks of treatment. The statistical method : ANOVA, $t$-test, pair $t$-test and $\chi^{2}$ were used.

Results:

1. Body weight in arm A was reduced from $88.8 \pm$ $22.82 \mathrm{~kg}$ to $80.17 \pm 19.87 \mathrm{~kg}$, in group B from $79.49 \pm$ 13.28 to $71.08 \pm 11.61 \mathrm{~kg}$, n.s. 
2. Body mass index reduced in group A from $32.29 \pm 5.79$ to $29.17 \pm 5.33 \mathrm{~kg} / \mathrm{m}^{2}$ in group B from $29.04 \pm 3.07$ to $26.25 \pm 2.74 \mathrm{~kg} / \mathrm{m}^{2}, p=0.52$

3. Total cholesterol was reduced in group A from $4.22 \pm$ 0.64 to $3.42 \pm 0.53 \mathrm{mmol} / \mathrm{l}$, in group B from $3.64 \pm 0.68$ to $3.23 \pm 0.54 \mathrm{mmol} / 1 p<0.05$

4. ApoB was reduced in group $\mathrm{A}$ from $0.84 \pm 0.16$ to $0.65 \pm$ 0.15 , in group B from $0.64 \pm 0.15$ to $0.52 \pm 0.12 p<0.05$

5. No effect to the blood pressure, $\mathrm{C}$ reactive protein and the other parameters were ascertained.

Conclusion: The decreasing of the total cholesterol, apolipoprotien B was more marked in the group of the volunteers with the supplementation of the omega 3 fatty acids than in the control group.

Support: The project was supported by the Grant of the Ministery of Agriculture, CZ, No QH 92307.

\section{INDIVIDUAL (PERSONALIZED) CARIES PREVEN- TION: 25 YEARS OF EXPERIENCE}

Kunin AA, Belenova IA, Moiseera NS

Therapeutic Dentistry Department of Voronezh N.N. Burdenko State Medical Academy of the Ministry of Public Health and Social Development of the Russian Federation

Basing on a great number of research works conducted by the Therapeutic Dentistry Department's staff, it was concluded that a clinical outcome of caries prevention appears to be influenced by a wide range and combination of individual parameters: level of metabolic processes in humans, human cardiovascular, endocrine and digestive systems state, $\mathrm{pH}$ value, oral fluid $\mathrm{pH}$, enamel and dentin metabolic processes activity, dental pulp response, periodontal condition and other aspects. Consequently, each patient needs to be treated individually according to his/her individual dental health. It raises the pertinent question: What exactly should be personalized and how? Answering that with respect to the scientific research, we came to the following conclusion: the preventive measures and treatment strategies must be clearly defined in preventive medicine.

A complete diagnostic examination is of top priority for effectiveness of further preventive measures. Our longstanding research activities have given us an option of developing, adapting to the practice, and implementing a minimized spectrum of research methods making it possible to detect individual cariogenic components. That is why we concluded that currently applied diagnostic methods are not personalized: they should be standard and unified for all patients examined. The individual cariogenic factors revealed the course of examination making personalized prevention and treatments possible. Therefore, it is strate- gically important that the diagnostic phase will be unified and the prevention and treatment phase will be personalized. We identified 52 factors related to caries initiation. Using a methodology of ranking, we have chosen 12 fundamental ones, based on which 12 caries prevention strategies eliminating individually detected caries-potentiating components were developed. For the last 15 years we have collected positive experience in person-oriented caries prevention programs used. It is important to mention that the most successful preventive strategies can be implemented solely by centers specialized in the field. Such a Center for Individual Caries Prevention was established in February 2004 on the basis of the Therapeutic Dentistry Department of N.N. Burdenko VSMA. The active scientific work enabled us to organize the first in the world International League of Individual (Personalized) Caries Prevention in 2005. The League's organizers were Voronezh N.N. Burdenko State Medical Academy, Dentistry Institute affiliated with N.N. Burdenko VSMA, the Johannes Gutenberg University of Mainz (Germany), companies producing dental equipment and products: «Hammacher» (Germany), «W\&H» (Austria), «DRC» (Switzerland-Russia), «Heraeus Kulzer» и «Zemaher» (Germany), «GlaxoSmithKline» (Germany), International Implantology and Esthetic Dentistry Forum (Mainz, Germany).

\section{INFLUENCE OF FLUORESCENCE AND ELECTRO- METHRY IN ESTIMATED CHARACTERISTIC AND REMINERALIZATION THERAPY OF TEETH}

Moiseeva NS

Voronezh N.N. Burdenko State Medical Academy

Studencheskaya str., 10, 394000, Voronezh, Russia

Development of physical factors of therapy has opened new possibilities of effective diagnostics of teeth allowing to define demineralization processes in enamel of the tooth and to raise an efficiency of remineralization therapy. Electrometric and light-emitting diode light as well as a preventive therapy of caries by remineralization gel (amino acids, calcium, vitamin $\mathrm{D}$, citrate - antibacterial component, etc.) are used.

Research data were collected from 60 persons, at the age of 18-20 years. Clinical research included traditional methods of inspection.

The parameters were defined electrometrically by G.G. Ivanova and V.K. Leontev (1980) technique. The lightemitting diode light examinations revealed the centers of demineralization (green light-emitting diode light) and secondary caries (red light-emitting diode light). The method of a luminescence has been developed by Therapeutic Stomatology VGMA of N.N. Burdenko.

The patient pool has been divided on two groups. Both groups underwent electrometric of enamel, the fluorescence 
method. 1st group underwent applications by gel with amino acids daily within 15 days; 2 nd group served as the control one. Medical supervision to both groups was performed during 1 year.

The analysis of the data collected has shown that significant positive therapeutic effects have been reached in the 1st group: the electrometric caries indicators have decreased on hillocks from 24.8 to $19.0 \mathrm{mcA}$, in fissures-from 38.5 to $29.4 \mathrm{mcA}$, on seal borders-from 41.2 to $27.8 \mathrm{mcA}$, on fragment enamels - from 41.2 to $27.8 \mathrm{mcA}$, and on vestibular surfaces-from 3.91 to $1.43 \mathrm{mcA}$. 